\title{
RETRACTED
}

Paper-Using Learning Analytics to Predict Students Performance in Moodle LMS

\section{Using Learning Analytics to Predict Students Performance in Moodle LMS}

\author{
https://doi.org/10.3991/ijet.v15i20.15915 \\ Yaqun Zhang $(\bowtie)$ \\ Shenyang Normal University, Shenyang, China \\ Tomsk State University, Tomsk, Russian Federation \\ 334812333@qq. com \\ Ahmad Ghandour \\ Al Ain University, Abu Dhabi, United Arab Emirates \\ Viktor Shestak \\ MGIMO University, Moscow, Russian Federation \\ Military University, Moscow, Russian Federation
}

This article has been retracted by the iJET editorial team:

The article on this page has been associated with fraudulent publication practices after its publication in iJET. The work could be linked to a criminal paper mill selling authorships and articles for publication in several online journals to paying customers.

The iJET editorial team was initially informed about the paper mill's fraudulent activities by Dr. Perron (University of Michigan) and his team on $08 / 03 / 2021$. The investigation results were published on RetractionWatch under https://retractionwatch.com/ author/perronetal/ on 12/20/2021. Based on the evidence provided by Dr. Perron and his team, the iJET editorial team considerably questions the paper's scientific integrity and legitimacy as part of the scientific body. Finally, iJET decided to retract the paper.

Neither iJET, Online-Journals.org, nor IAOE stands in any contact with the paper mill's fraudulent activities. We condemn such procedures and dissociate ourselves from any person or entity, which is knowingly or unknowingly part of it. 












